\title{
Significance of Drying Periods on Nitrate Removal in Experimental Biofilters
}

\author{
Daniel N. Subramaniam, Prasanna Egodawatta, Chaminda Gallage, Peter Mather and Jay Rajapakse \\ Queensland University of Technology, Brisbane, Queensland.
}

Received 201405 01, accepted 201408 25, published 20141021.

\begin{abstract}
Nitrogen is an important nutrient that can impact the quality of aquatic environments when present in high concentration. Even though low concentration levels of ammonium-nitrogen have been observed in laboratory studies in bioretention basins, poor removal or even the production of nitrate-nitrogen within the filter is often recorded in such studies. Ten Perspex biofilter columns of $94 \mathrm{~mm}$ (internal diameter) were packed with a filter layer, transition layer and a gravel layer. While the filter layer was packed to a height of $800 \mathrm{~mm}$, transition and gravel layers were packed to a composite height of $220 \mathrm{~mm}$ and operated with simulated stormwater in the laboratory. The filter layer contained $8 \%$ organic material by weight. A free board of $350 \mathrm{~mm}$ provided detention storage and head to facilitate infiltration. The columns were operated with different antecedent dry days $(0 \mathrm{~d}$ to $21 \mathrm{~d})$ and constant inflow concentration at a feed rate of $100 \mathrm{~mL} / \mathrm{min}$. Samples were collected from the outflow at different time intervals, between $2 \mathrm{~min}$ and $150 \mathrm{~min}$ from the start of outflow, and were tested for nitrate-nitrogen and total organic carbon. Washoff of organic carbon from the filter layer was observed to occur for $30 \mathrm{~min}$ of outflow. This indicated washoff of organic carbon from the filter itself. At the same time, a very low concentration of nitrate-nitrogen was recorded at the beginning of the outflow, indicating the effective removal of nitrate-nitrogen. We conclude that the removal of nitrate-nitrogen is insignificant during the wetting phase of a rainfall event and the process of denitrification is more pronounced during the drying phase of a rainfall event. Thus intermittent wetting and drying is crucial for the removal of nitrate-nitrogen in bioretention basins.
\end{abstract}

Keywords: nitrate-nitrogen, total organic carbon, bioretention basins, filter layer, intermittent wetting and drying.

\section{Introduction}

Stormwater biofilters, while quantitatively managing stormwater runoff, can also efficiently remove pollutants including some nutrients, suspended solids and heavy metals, preventing them from infiltrating stormwater runoff (Davis et al. 2003; Davis et al. 2006; Davis 2007; Davis et al. 2007; Blecken et al. 2008, 2009). Nutrients such as nitrogen, phosphorus and carbon can degrade water quality when present in high concentrations. Stormwater runoff has often been shown to contain high concentrations of nutrients that can ultimately pollute receiving waters (Ice 2004; Kim 2009). Stormwater management systems including bioretention basins are therefore required to increase nutrient removal.

Several studies have been conducted to assess the performance of bioretention basins in removing nutrients from stormwater runoff and they concluded that removal of nitrogen varies depending on the nitrogen species. For example, ammonium-nitrogen has been observed to be reduced in bioretention basins while the concentration of nitrate-nitrogen increased in the outflow when compared with the inflow (Davis et al. 2006; Bratieres et al. 2008; Blecken et al. 2011).

Unlike ammonium-nitrogen, which is transformed into nitrate-nitrogen under aerobic conditions via nitrification, or which can be adsorbed to negatively charged sites on the filter material, nitrate-nitrogen is removed only by a reduction process called denitrification (Davis et al. 2010). The process of denitrification reduces nitrogen compounds including $\mathrm{NO}_{3}{ }^{-}$and $\mathrm{NO}_{2}{ }^{-}$eventually to $\mathrm{N}_{2}$, under anoxic conditions and in the presence of organic carbon as an electron donor (Cheremisinoff 2002; von Sperling and Chernicharo 2005). These two crucial factors further restrict the process of denitrification in treatment systems when compared with nitrification.

Stratification of zones based on the levels of dissolved oxygen (aerobic to anaerobic with depth) in filter systems has been observed to develop with continuous feed and extensive growth of aerobic microbial communities (von Sperling and Chernicharo 2005). Since rainfall events are generally short in duration, bioretention basins often operate for a shorter time period when compared with water treatment filter systems. Furthermore,

Subramaniam, D., P. Egodawatta, C. Gallage, P. Mather and J. Rajapakse. 2014. "Significance of Drying Periods on Nitrate Removal in Experimental Biofilters." Journal of Water Management Modeling C381. doi: 10.14796/JWMM.C381.

(c) CHI 2014 www.chijournal.org ISSN: 2292-6062 
bioretention basins have been designed to transport stormwater rapidly through the system and hence the filter bed may not operate when the filter is saturated (Browne et al. 2008). In contrast, unsaturated filters have air pockets that inhibit the formation of anoxic or anaerobic zones. In addition, the fast transport of fresh stormwater through the system also rapidly distributes dissolved oxygen in the filter layer. Thus the filter layer may operate under aerobic conditions and, depending on the efficiency of microorganisms in the filter which consume dissolved oxygen, the filter may develop anoxic and anaerobic zones (Browne et al. 2008).

Davis et al. (2010) suggest that ammonium- and nitrate-nitrogen removal would not occur during the wetting phase of the event. They go on to suggest that ammonium-nitrogen is readily adsorbed to charged sites in the filter layer, and is subsequently nitrified to nitrate-nitrogen during the drying phase of the event. They support this view by reporting that higher nitrate-nitrogen concentrations are present in the outflow, as the residue of the nitrification of ammonium-nitrogen during the drying phase; that these remain in the system; and are washed off eventually during the next rainfall event. In order to enhance nitrate-nitrogen reduction in bioretention filters, past studies have added additional organic material and also designed a permanent saturated zone to provide electron donors and to induce anoxic conditions, respectively (Kim et al. 2003; Blecken et al. 2009, 2010).

The studies reported above, however, did not analyse the impact of the organic content of the filter layer on the efficiency of the denitrification process before adding more carbon source to the filter. Moreover, most of these studies assessed the performance of the systems based on the event mean averages of pollutant concentration in the outflow using extended and continuous feeding of the systems. An important factor in bioretention basins, however, is that they are subjected to sporadic intermittent wetting and drying periods. The focus of earlier studies has largely been on the wetting phase of an event, with only limissted attention being paid to the drying phase. Consequently this paper focuses on the drying phase of an event and analyses the effect of antecedent dry days and organic matter content in the filter layer on the performance of nitrate-nitrogen removal in bioretention basins.

\section{Methodology}

\subsection{Laboratory Scale Bioretention Basins}

Five Perspex columns, $94 \mathrm{~mm}$ internal diameter and $1.6 \mathrm{~m}$ long, were used as stormwater biofilter columns. Each column was packed according to standard guidelines developed by the Gold Coast City Council (Gold Coast City Council 2003; South East Queensland Healthy Waterways 2010). Materials for biofilter columns (filter media, transition zone and drain zone) were obtained from an industry standard material supplier in Brisbane and the Gold Coast, Australia (Figure 1).

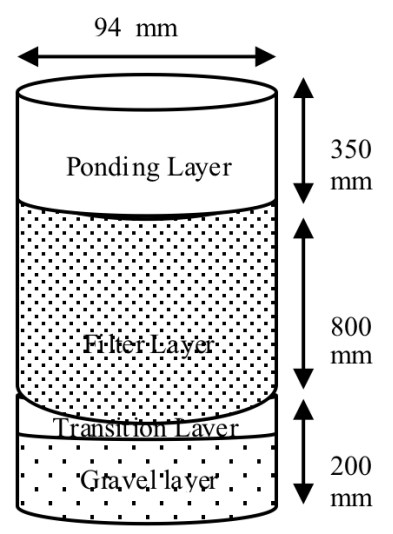

Figure 1 Schematic diagram of biofilter columns.

The constitution of the layers is as follows:

1. Filter layer: an engineered biofilter material of particle size $<1 \mathrm{~mm}, 8 \%$ organic material by weight.

2. Transition layer: sand with particle size ranging from $1 \mathrm{~mm}$ to $2 \mathrm{~mm}$, designed to prevent wash off of filter material;

3. Drain layer: gravel of particle size ranging from 2 $\mathrm{mm}$ to $5 \mathrm{~mm}$, serving as the drainage layer;

4. Ponding layer: a ponding zone of $350 \mathrm{~mm}$ above the filter layer was left to temporarily store stormwater and also to provide sufficient head for the process of infiltration; and

5. Vegetation: a vegetation layer is optional in bioretention basins and there are some actual biofilters in South-East Queensland that do not have vegetation other than turf grass (Figure 2). Nitrate-nitrogen uptake by plants is debated as if it could be a removal process compared to denitrification, which is a removal process (Payne et al. 2014). The current study therefore focuses on the removal of pollutants in the filter layer alone.

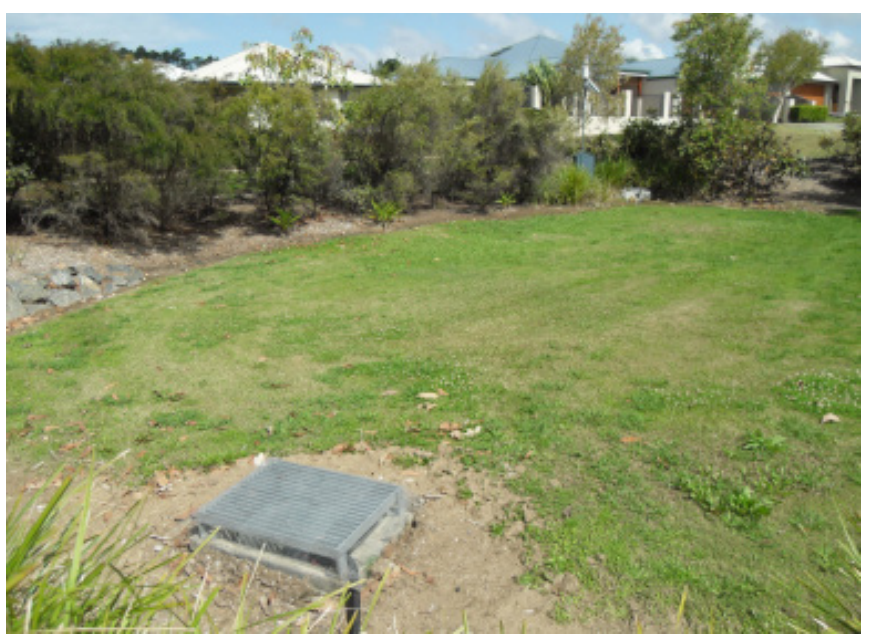

Figure 2 A bioretention basin in South-East Queensland. 
Columns were fed with tap water for 2 weeks (for $3 \mathrm{~h}$ at a feeding rate of $100 \mathrm{~mL} / \mathrm{min}$, twice a week) and stabilized. Column packing was designed so that zones settled to a height as shown in the diagram (Figure 1 above) within 2 weeks.

\subsection{Simulated Stormwater}

In order to regulate the quality of stormwater fed to the experimental columns, and to be consistent across the experimental schedule, simulated stormwater was generated in the laboratory and used for the experiments. Using simulated stormwater for controlled laboratory experiments has been a common practice and constituents for simulated stormwater in this study were determined based on past published studies (Davis et al. 2003; Kim et al. 2003). Simulated stormwater was prepared by mixing the following materials to tapwater:

1. Ammonium nitrate $\left(\mathrm{NH}_{4} \mathrm{NO}_{3}\right): 2.5 \mathrm{mg} / \mathrm{L}$ nitrogen, to represent ammonium and nitrate pollutants in stormwater;

2. Glycine $\left(\mathrm{C}_{2} \mathrm{H}_{5} \mathrm{NO}_{2}\right): 2.5 \mathrm{mg} / \mathrm{L}$ nitrogen, to represent organic nitrogen in stormwater; and

3. Montmorillonite and kaolinite (50:50 by weight): $100 \mathrm{mg} / \mathrm{L}$, to represent solids in suspension in stormwater.

\subsection{Experiments}

Columns were fed with simulated stormwater at a feeding rate of $100 \mathrm{~mL} / \mathrm{min}$ for $\sim 3 \mathrm{~h}$ in each event and were then left to drain. The feed rate was computed based on a 3 month average recurrence interval for the Gold Coast area that was $34 \mathrm{~mm} / \mathrm{h}$ rainfall, and based on the assumption that the area of the bioretention basin covered an estimated 3.5\% of the catchment area. The level of water in the ponding zone was maintained $\leq 350 \mathrm{~mm}$ above the filter layer. Since columns were not repacked between events, the sequence of events was numbered (EN, event number) to represent the age of the filter in field scale operations.

\subsection{Water Quality Monitoring}

Samples $(250 \mathrm{~mL}$ ) were collected from the inflow and tap water during each experimental trial. Additionally, samples $(250 \mathrm{~mL})$ were collected from the outflow stream at $2 \mathrm{~min}, 7 \mathrm{~min}, 12 \mathrm{~min}$, $20 \mathrm{~min}, 30 \mathrm{~min}, 60 \mathrm{~min}, 90 \mathrm{~min}, 120 \mathrm{~min}$ and $150 \mathrm{~min}$ from the beginning of outflow. Samples were tested for nitrate-nitrogen (4500-NO3-E) based on Standard Methods for Examination of Water and Wastewater (APHA 2005), and total organic carbon (3510-B of Standard Methods for the Examination of Water and Wastewater).

The experiment was repeated for different antecedent dry days ( $A D D$, the number of days between two rainfall events) varying from $0 \mathrm{~d}$ to $21 \mathrm{~d}$. Columns were observed to take approximately $16 \mathrm{~h}$ to stop draining completely after an event, and therefore 0 ADD was considered as an event that occurred within $\sim 24 \mathrm{~h}$ of the previous event.

\subsection{Soil Moisture Analysis}

In order to understand the dynamics of the moisture content of the filter layer, one bioretention column was fed with simulated stormwater and left to dry over a $40 \mathrm{~d}$ period. Filter samples were drawn from sampling ports at five different depths in the filter column $(50 \mathrm{~mm}, 100 \mathrm{~mm}, 400 \mathrm{~mm}, 750 \mathrm{~mm}$ and $800 \mathrm{~mm}$ from the top of the filter) at each different number of days of drying ( $0 \mathrm{~d}$ to $40 \mathrm{~d}$ ). Filter samples were analysed for the degree of saturation in accordance with AS 1289 B1.1 (Standards Australia 1977).

\section{Results and Discussions}

\subsection{Soil Moisture Profile During Drying}

Variation in the degree of saturation (soil moisture content) of the filter material at different depths is given in Figure 3. Each plot represents results on different ADD in days.

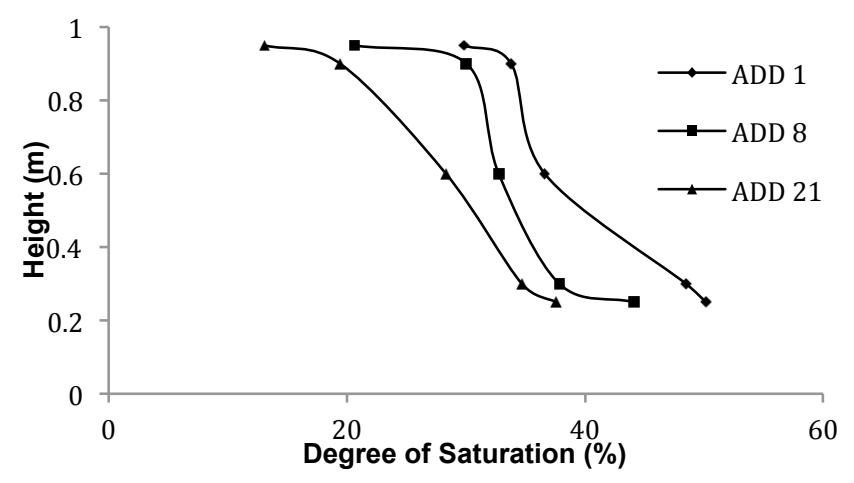

Figure 3 Moisture content profile of filter layer on different ADD and at different depths in the filter.

It is apparent from Figure 3 that the top layer in the filter (the first $10 \mathrm{~cm}$ ) dries rapidly, reaching the lowest moisture content over the shortest time frame, while bottom layers in the filter dry much more slowly. It is also evident from the soil moisture profile, that even after a $40 \mathrm{~d}$ drying period, the filter still holds a significant amount of moisture. The calculation of water retention in the filter zone showed that it held approximately $1.2 \mathrm{~L}$ to $0.6 \mathrm{~L}$ water in the column from $0 \mathrm{~d}$ to $40 \mathrm{~d}$ drying, respectively.

\subsection{Total Organic Carbon}

Total concentration of organic carbon (TOC) in the outflow was observed to be very high compared with the concentration of TOC in the inflow (Figure 4). This apparently results from the leaching of organic carbon from organic material in the filter layer. The leaching rate is higher in the first $10 \mathrm{~min}$, and thereafter gradually decreases and eventually settles at a relatively low concentration ( 10 ppm) after $\sim 30$ min from the start of the outflow, in all the events. In contrast, EN and the number of ADDs had no effect on the concentration of TOC once the first flush had settled. 


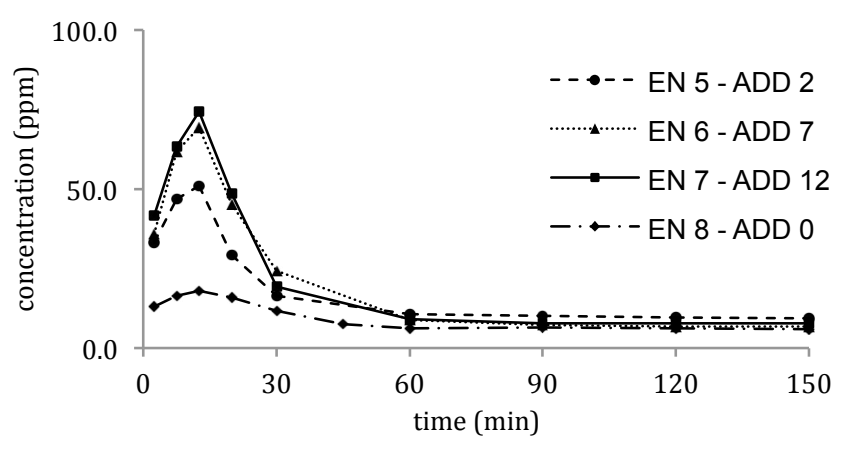

Figure 4 Concentration of TOC in the outflow with time.

\subsection{Nitrate-Nitrogen}

In contrast to the variation in concentration of TOC in the outflow with time, removal of nitrate-nitrogen was observed to be continuous across the experimental period (150 min), Figure 5a. Removal was observed, however, to decrease with time; the concentration of nitrate in the outflow steadily increased for the first $30 \mathrm{~min}$ to $60 \mathrm{~min}$ and then settled. After $60 \mathrm{~min}$, the outflow concentration was almost equal to that of the concentration in the inflow, indicating negligible removal.
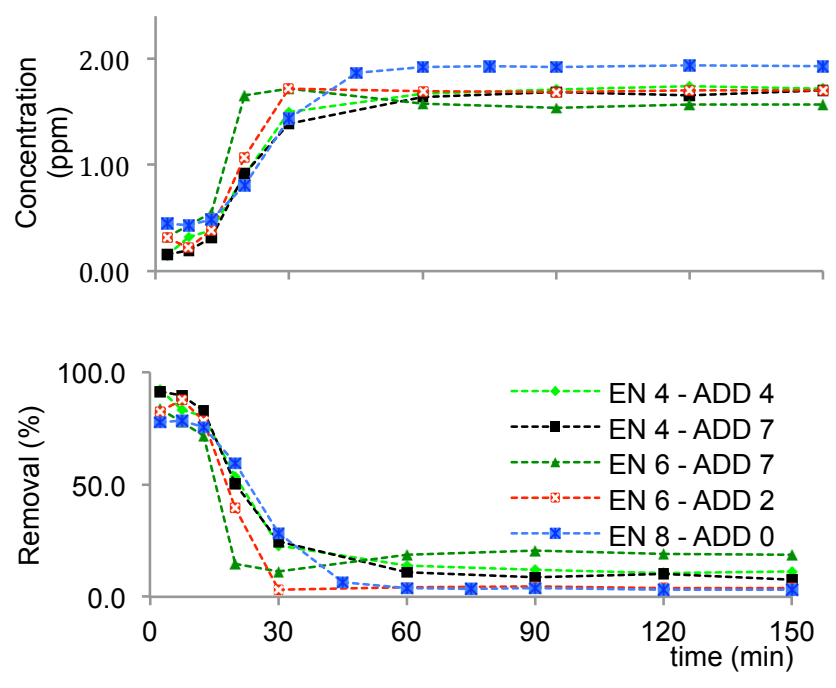

Figure 5 (a, upper) Concentration of nitrate-nitrogen in the outflow with time; (b, lower) removal of nitratenitrogen in the outflow with time.

Concentration of nitrate-ntirogen in the inflow was $2.0 \pm 0.23 \mathrm{ppm}$. In order to eliminate any bias in the analysis, influenced by small variation in the inflow concentration, the rate of nitrate removal was considered in subsequent statistical analyses (Figure 5b). Principal component analysis results showed that removal percentage of nitrate (from $7 \mathrm{~min}$ to $20 \mathrm{~min}$ ) was correlated negatively with ADD while the EN did not have a significant impact on the nitrate-nitrogen concentration in the outflow (results not shown). Furthermore, concentration of nitrate in the outflow at 2 min was not affected by either ADD or EN. This result suggests that ADD can have a significant effect on nitrate removal from a bioretention basin while the effect of EN was much less significant.

\subsection{Discussion}

Nitrate is a very stable compound in water treatment systems, and is only removed from a system by microorganisms assisting the process of denitrification, with moisture being crucial to the growth of these microorganisms (Lovieno and Baath 2008). We have also observed here that the filter still contains a significant amount of water during the drying phase. Therefore, during an event, nitrate-nitrogen removal can occur in bioretention basins, during the wetting phase or during the drying phase of the event. Concentrations of both nitrate-nitrogen and TOC (after $30 \mathrm{~min}$ to $60 \mathrm{~min}$ from the start of outflow) gradually approach a concentration comparable with concentration of nitrate-nitrogen and TOC in the inflow. At the same time, removal of nitrate-nitrogen is very rapid at the beginning of the outflow for all ADDs. The growth of microorganisms, in particular after long periods of starvation, will also need time to get reactivated and growth will continue with the availability of substrates. Thus, following a dry period when new stormwater enters the system, the immediate removal of nitrate-nitrogen should be low because it requires time for the microbial community to be reactivated and to multiply before nitrate-nitrogen is removed efficiently. While this should result in a gradual increase in nitrate-nitrogen removal over time, in the current study we observed the reverse. In addition, as discussed earlier, the column can operate under both unsaturated and aerobic conditions. This further restricts the potential for denitrification during the wetting phase of an event.

Furthermore, the washoff of organic carbon at the beginning of outflow, and the retention of moisture in the soil pores, suggest that microbial degradation may be high during the drying phase, which would in turn deplete dissolved oxygen levels in the retained water. Thus there is potential for the development of micro-anoxic environments in the pore and capillary water (Haider and Schaffer 2009). The production of labile carbon, a process that breaks down the complex structures of organic matter, which also occurs during the drying phase (a phenomenon known as the Birch Effect), can further facilitate the process of denitrification by providing substrate and electron donors (Birch 1958; Jarvis et al. 2007). Therefore nitrate-nitrogen in water that is retained in the pores during the drying phase of the event is most likely to undergo denitrification at this stage, rather than during the wetting phase of an event. This is further affirmed by a strong correlation observed between the concentration of TOC and nitrate-nitrogen removal in the first $30 \mathrm{~min}$ of the outflow. Water retained in the system, where concentration of nitrate-nitrogen is low and concentration of TOC is high, will eventually mix with the stormwater from a subsequent event and contribute to an outflow. Mixing may happen gradually, a process that would account for a gradual increase in nitrate-nitrogen and a gradual decrease in TOC in the outflow over time. 


\section{Conclusions}

Intermittent wetting and drying is a unique property of bioretention systems which plays a major role in removal of nitrate-nitrogen from stormwater. Nitrate-nitrogen is not removed during the wetting phase of an event; rather, the process of denitrification is more active during the drying phase of an event. The drying phase of an event cycle assists degradation of complex structured organic material into labile organic carbon that is easily consumed by microorganisms, the Birch effect. This process, together with moisture in the soil pores, facilitates microbial growth in the system that will in turn deplete dissolved oxygen levels and produce micro-anoxic environments. The development of such zones allows the growth of anoxic and anaerobic microorganisms that assist with the removal of nitrate-nitrogen from stormwater runoff. The significant contribution to nitrate-nitrogen removal during the dry phase of events needs to be accounted for in performance analysis and the design of biofilters where they are currently based solely on nitrate-nitrogen removal during the wet phase of events.

\section{Acknowledgments}

We thank River Sands Pty Ltd for providing the bioretention basin material for this experiment and for their support. I would like to thank the laboratory staff of Queensland University of Technology for their support in the experiments. I would also like to thank the reviewers for their valuable comments.

\section{References}

APHA (American Public Health Association). 2005. Standard Methods for the Examination of Water and Wastewater. Washington, DC: American Public Health Association.

Birch, H. F. 1958. "The Effect of Soil Drying on Humus Decomposition and-nitrogen Availablity." Plant and Soil 10 (1): 9-31.

Blecken, G.-T., J. Marsalek and M. Viklander. 2011. “Laboratory Study of Stormwater Biofiltration in Low Temperatures: Total and Dissolved Metal Removals and Fates." Water Air Soil Pollution 219:303-17.

Blecken, G.-T., Y. Zinger, A. Deletic, T. D. Fletcher and M. Viklander. 2008. "Heavy Metal Removal by Stormwater Biofilters: Can It Withstand Alternative Wetting and Drying Conditions?" In 11th International Conference on Urban Drainage, Edinburgh, Scotland, 2008.

. 2009. "Impact of a Submerged Zone and a Carbon Source on Heavy Metal Removal in Stormwater Biofilters." Ecological Engineering 35: 769-78.

. 2010. "Effect of Retrofitting a Saturated Zone on the Performance of Biofiltration for Heavy Metal Removal-Preliminary Results of a Laboratory Study." Paper presented at NOVATECH, France, 2010.

Bratieres, K., T. D. Fletcher, A. Deletic and Y. Zinger. 2008. “Nutrient and Sediment Removal by Stormwater Biofilters: A Large
Scale Design Optimisation Study." Water Research 42: 3930-40. doi:10.1016/j.watres.2008.06.009.

Browne, D. , A. Deletic, M. Gavin, G. Mudd and T. D. Fletcher. 2008. "A New Saturated/Unsaturated Model for Stormwater Infiltration Systems." Hydrological Processes 22: 4838-49.

Cheremisinoff, N. P. 2002. Handbook of Water and Wastewater Treatment Technologies. Woburn, MA: Butterworth-Heinemann.

Davis, A. P. 2007. "Field Performance of Bioretention: Water Quality." Environmental Engineering Science 24 (8): 1048-64.

Davis, A. P., H. Li and P. S. Jones. 2007. “Toxic Compound Capture and Fate in Bioretention." Paper presented at NOVATECH, France, 2007.

Davis, A. P., M. Shokouhian, H. Sharma and C. Minami. 2006. “Water Quality Improvement through Bioretention Media: Nitrogen and Phosphorus Removal." Water Environment Research 78 (3): 284-93.

Davis, A. P., M. Shokouhian, H. Sharma, C. Minami and D. Winogradoff. 2003. “Water Quality Improvement through Bioretention: Lead, Copper and Zinc Removal." Water Environment Research 75 (1): 73-82.

Davis, A. P., R. G. Traver and W. F. Hunt. 2010. “Improving Urban Stormwater Quality: Applying Fundamental Principles." Journal of Contemporary Water Research \& Education 145:3-10.

Gold Coast City Council. 2003. Goldcoast Planning Scheme 2003 Policy 11-Land Development Guidelines.

http://www.goldcoast.qld.gov.au/gcplanningscheme_policies/policy_11.html\#guidelines.

Haider, K. and A. Schaffer. 2009. Soil Biochemistry. Enfield, NH: Science Publishers.

Ice, G. 2004. “History of Innovative Best Management Practice Development and Its Role in Addressing Water Quality Limited Waterbodies." Journal of Environmental Engineering 130 (6): 684-9.

Jarvis, P., A. Rey, C. Petsikos, L. Wingate, M. Rayment, J. Pereira, J. Banza, J. David, F. Miglietta, M. Borghetti, G. Manca and R. Valenti. 2007. “Drying and Wetting of Mediterranean Soils Stimulates Decomposition and Carbon Dioxide Emission: The Birch Effect." Tree Physiology 27: 929-40.

Kim, H., E. A. Seagren and A. P. Davis. 2003. “Engineered Bioretention for Removal of Nitrate from Stormwater Runoff." Water Environment Research 75 (4): 355-67.

Kim, Y.-K. 2009. "Nutrient Sources and Dynamics in the Parafield Stormwater Harvesting Facility and Implication to Water Quality Control." Adelaide, SA: University of Adelaide.

Lovieno, P. and E. Baath. 2008. “Effect of Drying and Rewetting on Bacterial Growth Rates in Soil." Federation of European Microbiological Societies 65: 400-7. 
Payne, E. G. I., T. D. Fletcher, P. L. M. Cook, A. Deletic and B. E. Hatt. 2014. "Processes and Drivers of Nitrogen Removal in Stormwater Biofiltration." Critical Reviews in Environmental Science and Technology 44 (7): 796-846.

South East Queensland Healthy Waterways. 2010. Construction and Establishment Guidelines: Swales, Bioretention Systems and Wetlands Version 1.1. Brisbane, QLD: Healthy Waterways/Water by Design WSUD.

http://waterbydesign.com.au/ceguide/
Standards Australia. 1977. AS 1289.B1.1-1977 Methods of Testing Soil for Engineering Purposes - Part B - Soil Moisture Content Tests - Determination of the Moisture Content of a Soil - Oven Drying Method Standard Method. Sydney: Standards Australia.

von Sperling, M. and C. A. de L. Chernicharo. 2005. Biological Wastewater Treatment in Warm Climate Regions, Vol. 1. London: IWA Publishing. 